\title{
TRADUTOR E INTÉRPRETE DE LÍNGUA BRASILEIRA DE SINAIS: EXPERIÊNCIAS NARRADAS NO ESTADO DO RIO GRANDE DO SUL
}

\author{
BRAZILIAN SIGN LANGUAGE TRANSLATORS AND INTERPRETER: \\ EXPERIENCES IN THE STATE OF RIO GRANDE DO SUL, BRAZIL
}

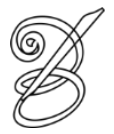 \\ Lucas de Almeida SOARES ${ }^{\mathrm{i}}$ \\ Instituto Federal Sul-Rio-Grandense \\ Saionara dos Santos FIGUEIREDO ${ }^{\text {ii }}$ \\ Instituto Federal de Santa Catarina
}

Resumo: Este artigo é fruto das narrativas contadas por uma amostragem de Tradutores e Intérpretes de Libras TILS - em cidades do Rio Grande do Sul. A partir da análise dessas falas, pretendeu-se expor a fragilidade que esse profissional se encontra; de um lado, o seu cliente, que exige uma fluência, domínio linguístico e certificação; de outro lado, os impasses de algumas instituições que não entendem o papel social deste profissional. Através das experiências coletadas a partir de entrevistas realizadas, enumerou-se categorias de análise, que facilitou a organização e análise dos dados. Percebeu-se que, apesar de haver pesquisas na área de tradução/interpretação da Libras, ainda há escassez de estudos sobre o profissional que a realiza. Sugere-se, portanto, que haja debate e pesquisa constante que avalie as condições de trabalho na qual a profissão é subjugada, além da legislação vigente, garantindo a dignidade do sujeito neste contexto.

Palavras chave: Intérprete de Libras. Formação profissional. Regulamentação da profissão. Código de Ética. Interpretação educacional.

Abstract: This article is the result of the narratives told by a sample of Translators and Interpreters of Libras TILS - in cities of Rio Grande do Sul. From the analysis of these lines, it was intended to expose the fragility that this professional is; on the one hand, its client, who demands fluency, linguistic control and certification; on the other hand, the impasses of some institutions that do not understand the social role of this professional. Through the experiences gathered from interviews conducted, categories of analysis were enumerated, which facilitated the organization and analysis of the data. It was noticed that, although there are researches in the area of translation / interpretation of Libras, there is still a shortage of studies about the professional that performs it. It is suggested, therefore, that there be debate and constant research that evaluates the conditions of work in which the profession is subjugated, in addition to the current legislation, guaranteeing the dignity of the subject in this context.

Keywords: Interpreters. Qualification. Regulation. Code of ethics; Educational Interpretation.

RECEBIDO EM: 05 de julho de 2017

ACEITO EM: 04 de junho de 2018

PUBLICADO EM: janeiro 2019

SOARES, FIGUEIREDO. Tradutor e Intérprete de Língua Brasileira de Sinais: experiências narradas no estado do Rio Grande do Sul

Belas Infiéis, v. 8, n. 1, p. 75-92, 2019. DOI: 10.26512/belasinfieis.v8.n1.2019.22618 


\section{Introdução}

$\mathrm{N}$

este artigo aborda-se a experiência de alguns $\operatorname{TILS}^{1}$, que trabalham no contexto pedagógico formal, contadas em entrevistas. Estes sujeitos puderam narrar suas vivências e conseguiram relacioná-las com a conjuntura social e política em que estão localizados. A pesquisa ocorreu com TILS do estado do Rio Grande do Sul.

Percebe-se que as funções laborais de um TILS estão envoltas à desafios profissionais, lizadas, além das conquistas no campo dos direitos trabalhistas, reconhecimento e visibilidade. Alguns estudos cerceiam a profissão do TILS; no entanto, percebe-se a escassez de narrativas, contadas pelos próprios TILS, sobre como estes indivíduos significam suas experiências e histórias. Sabendo de pesquisas e discussões que giram em torno do trabalho desse profissional (ALBRES E LACERDA, 2006, 2009, 2013; BELÉM, 2010; CONSTANCIO, 2010; CÓRDOVA, 2009; COSTA, 2008; GURGEL, 2010; LACERDA, 2002, 2006, 2008, 2010; MARTINS, 2009; QUADROS, 2002, 2004; SANTOS, 2010; SOUZA, 2010, entre outros); todavia, as questões de subjetividade destes profissionais permanecem em aberto. A temática que envolve a história de vida por trás do profissional TILS ganha contornos complexos quando se pensa que este está inserido numa comunidade de língua e cultura diferentes, que influenciam sua historicidade e constituição. Essa constituição e as contradições envolvendo a profissão e a subjetividade do/da TILS vêm sendo alvo de alguns estudos (BARAZZUTTI, 2009; NICOLOSO, 2010, PASSOS, 2010; ROSA, 2005; SANTOS, 2006 por exemplo).

Apesar da profissão do Tradutor e Intérprete de Libras já ter sido recentemente reconhecida sob o n $^{\circ}$ 261425, na CBO (Classificação Brasileira das Ocupações) e legalizada através da Lei 12.319, de 2010, ainda é notável que haja certa desvalorização desta. Em muitos dos casos, falta conhecimento do que esta signifique, principalmente porque a Língua Brasileira de Sinais, uma das línguas de atuação destes sujeitos, ainda não é completamente reconhecida pela população brasileira.

Segundo Santos (2013), vê-se a desvalorização do profissional TILS, percebidas também pelas falas dos próprios surdos. A luta ainda é por jornadas dignas de trabalho, remuneração adequada, valorização do plano de carreira, trabalho em duplas, e consequentemente, por uma regulamentação formal da profissão; assim, o profissional pode obter um melhor desempenho em seu campo de trabalho.

Portanto, a realidade desses profissionais ainda carece de atenção e cuidado. As vozes dos TILS também merecem ser ouvidas, para que se possa entender o contexto da profissão que 
escolheram. Neste contexto que desenvolve-se este artigo, com base bibliográfica de autores como: Anater \& Passos (2010), Masutti \& Santos (2008), Quaresma E Boni (2005), Russo (2009), Pereira (2008), Braga \& Trindade (2007), Laguna (2008), Santos (2012), Santos (2013), Martinez \& Paraguay (2003), Santos (2006), Albres (2015; 2016), embasando as falas dos intérpretes.

Apresenta-se, portanto, a metodologia de coleta de dados, que cerceou este estudo.

\title{
2. Metodologia de pesquisa
}

Trata-se de uma pesquisa de cunho qualitativo, que foi realizada no ano de 2013 e posteriormente analisada teoricamente. Essa pesquisa oportunizou a seis TILS que trabalham na cidade de Rio Grande/RS contarem suas histórias. A faixa etária dos participantes era de 20 a 45 anos de idade. Estes sujeitos possuem experiências de trabalho variadas, alguns transitando pela profissão há muito tempo; outros de formação recente e inacabada.

Para a coleta de dados, utilizamos entrevistas estruturadas. Segundo Quaresma e Boni (2005) estes questionários são previamente estruturados, para analisar posteriormente as semelhanças das respostas, onde não é necessário o entrevistador estar presente no momento da coleta. Esses dados podem ser fornecidos através de correio ou de um portador. Também, este método permite ao entrevistado uma liberdade de anonimato, fazendo com que os sujeitos de pesquisa se sintam livres para opinar.

\begin{abstract}
Mesmo sofrendo muitas críticas o questionário continua sendo muito utilizado nas diversas áreas. Algumas desvantagens da sua utilização são: a percentagem de retorno dos questionários enviados pelo correio geralmente é pequena e quando a devolução é tardia prejudica o andamento da pesquisa. Muitas vezes há um número grande de perguntas sem respostas. Outra desvantagem é a dificuldade de compreensão da pergunta por parte do respondente quando o pesquisador está ausente. (QUARESMA; BONI 2005; p 74)
\end{abstract}

As entrevistas escritas foram realizadas como meio mais prático para este artigo, facilitando assim, o pouco tempo para desempenhá-lo. Neste caso, com o questionário pronto, observou-se que nem todos responderam a todas as perguntas realizadas, por falta de entendimento das perguntas, mesmo havendo suporte por parte dos pesquisadores. Também, houve resumo de suas respostas feitas de maneira escrita, onde alegaram que seria mais dispendioso se citassem muitos detalhes. Salienta-se que o suporte dado pelos pesquisadores era presente e todos os entrevistados tiveram total liberdade de perguntar e questionar em

SOARES, FIGUEIREDO. Tradutor e Intérprete de Língua Brasileira de Sinais: experiências narradas no estado do Rio Grande do Sul

Belas Infiéis, v. 8, n. 1, p. 75-92, 2019. DOI: 10.26512/belasinfieis.v8.n1.2019.22618 
qualquer momento da pesquisa. Os entrevistados que optaram em levar o questionário para casa ainda assim, receberam suporte por parte dos pesquisadores,

Os dados foram coletados através de questionário dissertativo, onde foram feitas questões sobre o código de ética, postura, conquistas e desafios. Foi impresso um questionário para cada participante; a maioria respondeu na mesma sala, onde nesse momento, o entrevistador estava à disposição para qualquer eventual dúvida. Alguns ficaram inibidos por não conhecer alguns dados básicos para responder as questões propostas. Entretanto, cabe salientar que os entrevistados responderam de forma distinta e não houve cópia nas respostas uns dos outros. Além disso, todos tiveram discrição e zelo no anonimato das respostas.

Utilizou-se um questionário dissertativo, com oito perguntas, que foram escolhidas para identificar o profissional TILS que há no mercado de trabalho do Rio Grande do Sul, com o objetivo de ver a diferença do profissional recém-formado para o que já atua há algum tempo, no que tange a suas vivências. As perguntas realizadas foram:

Os TILS receberam os questionários e ficaram surpresos pelo termo de consentimento e zelo fornecido, porém, sentindo-se mais à vontade em responder as questões, por saberem que estavam com garantias que o anonimato seria mantido.

Assim, com a metodologia definida, passamos a análise dos dados.

\section{Sujeitos da pesquisa e Análise dos dados}

Abaixo um gráfico que define o mapeamento dos TILS que participaram da pesquisa, com idade, quantitativo de horas de trabalho/semana e tempo de experiência de trabalho:

Gráfico 1 - Mapeamento dos TILS participantes da pesquisa.

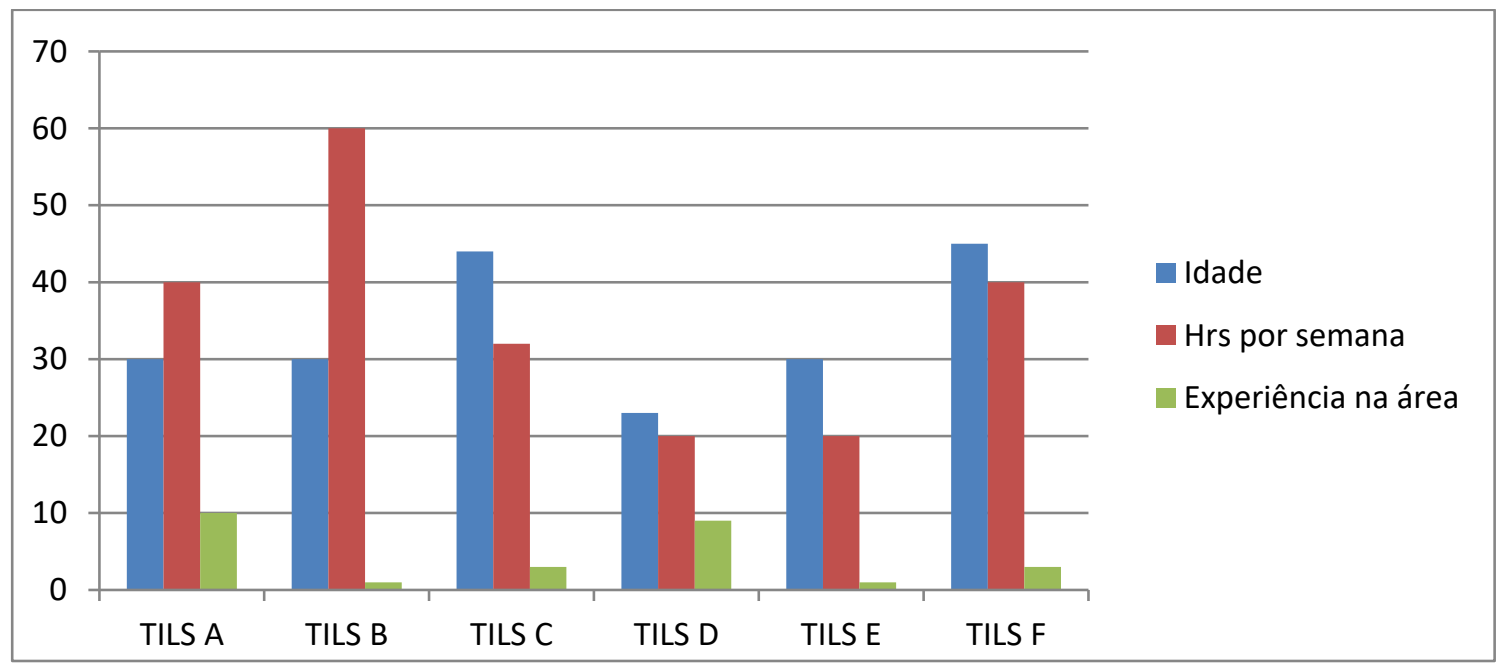

Elaboração: Soares e Figueiredo

SOARES, FIGUEIREDO. Tradutor e Intérprete de Língua Brasileira de Sinais: experiências narradas no estado do Rio Grande do Sul

Belas Infiéis, v. 8, n. 1, p. 75-92, 2019. DOI: 10.26512/belasinfieis.v8.n1.2019.22618 
Fazer tal tabela foi necessário para facilitar a análise dos dados. Percebe-se que, dependendo do tempo de experiência de trabalho, alguns já têm ideias amadurecidas do que seja a vivência como TILS. Além disso, os sujeitos com maior carga horária semanal apresentaram uma maior quantidade de insatisfações, principalmente pelo fato do cansaço e a busca incansável de melhoria salarial. Conforme Martinez e Paraguay (2003):

Trabalhadores insatisfeitos demonstraram ser mais susceptíveis à ansiedade depressiva em situações difíceis, o que provavelmente dificultaria a organização das tarefas e seu desempenho, e se ressentiam dos efeitos do estresse causado por sobrecarga, apresentando sintomas como dores de cabeça, cansaço, corpo tenso, fraqueza muscular e dificuldade para respirar com mais freqüência do que os trabalhadores satisfeitos " (MARTINEZ; PARAGUAY, 2003, p. 70)

Contudo, os profissionais que apresentam menor tempo de atuação apresentam mais empolgação pela profissão, mas são cientes dos impasses profissionais, por exemplo, desvalorização profissional e desafios tradutórios/interpretativos. A atitude que Pérez-Ramos (1980) descreve como "disposição para atuar e assumir posição perante determinadas situações" (Pérez-Ramos, 1980, p. 22), é percebida nos TILS com menos tempo de serviço, ou seja:

[...] a combinação de conceitos, informações e emoções que resultam em uma resposta favorável ou desfavorável com respeito a uma pessoa em particular, grupo, idéia, evento ou objeto e que, por serem deriva das de crenças, são poderosas influências sobre o comportamento e a aprendizagem (Campbell, 1999). Portanto, se atitudes são disposições para agir, decorrentes de conceitos, informações e emoções, podemos considerar que algumas atitudes podem ser decorrentes da satisfação no trabalho, mas não a sua definição. (MARTINEZ; PARAGUAY, 2003, p. 68-69).

Por outro lado, todos os entrevistados foram unânimes em falar sobre a importância da regulamentação da profissão. A maior preocupação dos TILS entrevistados foi a busca por estabilidade financeira, conseguida através do registro em carteira de trabalho e da garantia do trabalho em dupla, sendo essa última especificidade não amparada ainda pela legislação. Porém, diversas instituições reconhecem e oficializam tal trabalho realizado em dupla, como no caso do Instituto Federal Sul Riograndense que viabiliza o trabalho em dupla pela qualidade do ato tradutório e também da qualidade de vida dos profissionais atuantes. Ressaltando a importância do trabalho em dupla, Magalhães Júnior (2007) disserta que:

A principal razão para se trabalhar a dois é a absoluta atenção exigida no ofício. Eventos desafiadores com grande densidade de conteúdo apresentando em alta velocidade, requerem dos intérpretes total foco na conferência. [...]. Está provado que o ser humano só é capaz de manter níveis ótimos de atenção por curtos períodos de 
tempo. Trabalhando em dupla, os intérpretes têm a possibilidade de se revezar a cada 20 ou 30 minutos, permitindo com isso que cada um dê o máximo de si quando chegar sua vez (MAGALHÃES JUNIOR, 2007, p. 108)

Após essa visão geral de como a análise foi realizada e como o preenchimento dos questionários se deu, chega-se a alguns tópicos principais relatados: Quantitativo de horas; Realidade regional da profissão; Realidade da atuação como TILS; Regulamentação Profissional e Código de Ética. Esses aspectos serão aprofundados nos tópicos a seguir.

\title{
3.1 Sobre a área da tradução e interpretação de Língua Brasileira de Sinais
}

Atualmente que a principal luta da comunidade surda é por uma educação bilíngue de qualidade, que contemple aspectos culturais e identitários das pessoas surdas. Nesse aspecto, enquanto a criação das escolas bilíngues não é amplamente difundida no país, a presença dos TILS supre a necessidade inclusiva proposta pela Lei de Diretrizes e Bases 9394/96. MASUTTI E SANTOS (2010) dissertam acerca da profissão TILS e seu principal enfoque:

\begin{abstract}
A área de tradução em Língua de Sinais vem sendo problematizada nos meios acadêmicos atualmente com mais intensidade. Isso ocorre principalmente porque está havendo uma pressão dos movimentos surdos impulsionando a abertura dos espaços públicos às diferenças e a pesquisa relacionadas aos Estudos Surdos, o que fortalece a inserção de questões culturais éticas e políticas nas pautas reivindicatórias. (MASUTTI E SANTOS 2010, p 149)
\end{abstract}

Conforme Massutti e Santos (2010), é notório que com a inserção do sujeito surdo nos ambientes pedagógicos e acadêmicos, automaticamente a acessibilidade torna-se necessária, inserindo também os tradutores/intérpretes neste contexto. No caso desta pesquisa, um dos comentários feitos pelos TILS foi a falta de embasamento teórico dos surdos ao chegar a uma determinada etapa educacional, dificultando o ato tradutório/interpretativo. Por outro lado, nem todos os TILS possuem nível profissional para atuar em determinadas áreas acadêmicas.

Sobre isso, o sujeito "C" relata: "é gratificante saber que de alguma forma estamos contribuindo para o crescimento da nossa categoria". Conforme essa afirmação, percebe-se que o profissional se sente estimulado em saber que é útil no ato tradutório; apesar de trabalharem com mediação comunicativa, são acima de tudo, humanos. Como Pereira (2008) disserta sobre as multi-influências que um tradutor/intérprete pode exercer:

Ser intérprete é ser, intrinsecamente, um profissional atormentado por ter que estar presente e fingir-se invisível, algo ainda mais impensável para um intérprete de uma 
língua que é percebida prioritariamente pelo canal visual, como uma língua de sinais; e por não poder ser o "eu" nem o "tu" plenamente, por estar sempre em uma posição instável e escorregadia de um simbiótico locutor-interlocutor. Estes conflitos são maximizados por estereótipos dos quais é difícil nos livrarmos, tais como o velho e surrado traduttori, tradittori, que coloca a profissão sob permanente desconfiança, pois se algo vai mal no ato de linguagem, o primeiro a ser apontado como culpado é o intérprete. (PEREIRA 2008, p. 137)

Pereira (2008) expõe, portanto que, mesmo que haja gratidão por parte dos TILS por participarem do processo de ensino-aprendizagem de alguém, ainda assim a responsabilidade também recai sobre o mesmo diante do desenvolvimento (ou não) do aluno. Apesar dessa responsabilidade, o profissional deve permanecer neutro e imparcial, sendo este um desafio ético diário. Albres (2015) relata que:

[...] Na escola o intérprete é quem conhece as especificidades linguísticas da pessoa surda, quem sabe se comunicar com o aluno surdo, quem pode colaborativamente com o professor, criar condições favorecedoras de acesso aos conteúdos curriculares aos alunos surdos (LACERDA, 2000). (ALBRES, 2015, p. 53).

Em algumas situações já vividas pelo intérprete, é de se notar que alguns se sentem injustiçados por serem culpados de determinadas situações, como por exemplo, o bom desempenho do surdo em atividades escolares. Nesta pesquisa, todos os sujeitos afirmarem se sentirem incomodados ao receberem essa atribuição e responsabilidade. Muitos citaram que são vistos como "responsáveis" pelo surdo, independe de curso e idade. O sujeito D afirma que muitas vezes, mesmo que informalmente, os TILS são vistos como uma espécie de “acompanhantes" do aluno surdo, tendo a necessidade de chamar a atenção em questão de mal comportamento, lembrá-lo de datas, entrega de materiais, funções estas que não caracterizam o tradutor/intérprete.

Além disso, observa-se que os TILS participantes mostram grande diversidade de carga horária semanal, entre $20 \mathrm{~h}$ e $60 \mathrm{~h}$ de trabalho. Entretanto, pode-se perceber que, independente da carga horária, todos mostram-se insatisfeitos: ora quem trabalha 20 horas (gostaria de atuar 40 horas); ora quem trabalha 60 horas (gostaria de atuar 40 horas). Ambos os casos provocam e nos fazem refletir sobre estas vivências.

É notável que, quem atua 60 horas por semana tem insatisfações de dores musculares, cansaço e qualidade de tradução/interpretação comprometida. Por exemplo, o sujeito F expõe que sua maior percepção de dor muscular é nos ombros e no punho. Todos os TILS que trabalham $60 \mathrm{hrs}$ o fazem para que o salário seja complementado, ou seja, se submetem a maior 
probabilidade de se adquirir uma doença do trabalho/lesão. No caso dos TILS que atuam apenas 20 horas por semana relatam insatisfação salarial, além de também relatarem início de dores musculares. Percebe-se que ambas situações exigem um melhor salário para atuação, somente de 20 horas, ou consecutivamente 40 horas e $60 \mathrm{hrs}$.

De acordo com Braga e Trindade (2007, p 2) um dos grandes problemas da profissão é a LER - Lesão por Esforço Repetitivo, o qual está inserido historicamente desde o século XVII caracterizado como "distúrbios e traços uma causa ocupacional" (BRAGA E TRINDADE, 2007, p 2).

Diante das falas dos sujeitos, observamos que a todos os profissionais que atuam $60 \mathrm{hrs}$ por semana sofrem e reclamam de lesões pelo esforço interpretativo/tradutório. Braga e Trindade (2007) complementam:

[...] tendo em vista que esta parcela da população após concluir o ensino escolar almejará o ensino superior, oferece recursos acadêmicos adequados, incluindo intérpretes da Língua Brasileira de Sinais. Em relação ao trabalho das intérpretes que desenvolvem tarefas baseadas em movimentos repetitivos de membros superiores e com consequentes queixas diretas [...]. (BRAGA; TRINDADE 2007, p 02)

$\mathrm{O}$ sujeito " $\mathrm{F}$ " menciona que percebe suas dores musculares quando não atua em dois turnos, o que ocorre por haver folga em algum dia da semana. A pesquisa de Braga e Trindade (2007), em seu artigo, foi realizada com surdos usuários da Língua e TILS, onde foi constatado que os surdos dificilmente apresentaram desconforto muscular, diferente dos TILS, os quais a maioria apresenta em algum momento, desconforto, onde:

[...] As questões específicas para indivíduos que apresentaram dor, não fazem parte da tabela de análise dos dados dos alunos surdos, pois nenhum surdo apresentava dor, apenas 4destes relataram sentir um certo cansaço nos membros envolvidos quando há necessidade de intensa sinalização, porém, isto acontece de forma rara e não acaba sendo exatamente uma dor e sim um desconforto repentino de intensidade 01 dos membros (BRAGA; TRINDADE, 2007, p. 05).

A partir das colocações das pesquisadoras, percebe-se que a dor muscular é mais focada nos profissionais TILS, por estes não serem nativos naturais da Língua de Sinais, apresentando desconfortos peculiares e necessidade de pausas; diferentemente dos surdos analisados, os quais possuem a Libras como primeira língua, sendo sua sinalização algo natural. Mesmo os TILS que possuem contato prévio com a língua, sentem desconfortos, causados pelos movimentos 
contínuos realizados, fazendo com que as pausas do uso da Língua no contexto tradutório/interpretativo sejam necessárias.

\subsection{Sobre a regulamentação e características da profissão}

Atualmente os TILS continuam a lutar pela regulamentação da profissão, pois temos o reconhecimento através da Lei Federal 12.319/2010. Entretanto, faltam detalhes aprofundados sobre as especificidades atuais da profissão, como por exemplo, a necessidade do trabalho em equipe, horários de estudos para melhoria do ato tradutório, com acesso prévio ao que vai ser abordado durante sua tradução/interpretação, gerando diversas opiniões e posicionamentos tanto dos TILS, quanto das instituições que os contratam.

Entre tantas lutas que é feita pelos profissionais, temos a questão da formação, como expões SANTOS (2006):

O grupo de ILS vem desenvolvendo, nos últimos anos, discussões que compõem parte da política cultural que as pessoas surdas têm traçado, em especial solicitando formação e qualificação dos trabalhos. No entanto, essas discussões ganharam pouca visibilidade nacional, porque a carência dos materiais científicos e o interesse do governo, há pouco atrás, não era o de qualificar o ILS. Um exemplo dessa afirmação é a falta de registro sobre a história de como os ILS se constituíram [...]. (SANTOS, 2006, p.68)

É exposto que a formação dos TILS não é tão exigida como deveria, justamente pela Libras ser uma língua recente e, todos os desdobramentos a partir do reconhecimento desse status por Lei ocorrerem de maneira gradual. Além disso, não há um padrão de formação compatível com as necessidades atuais dos surdos, onde muitas vezes TILS são contratados com cursos simplórios da língua. A luta, portanto, excede apenas a comunidade TILS, incluindo também os sujeitos surdos.

Sobre isso, o sujeito A percebe que realmente há uma pequena defasagem na questão da certificação, ou até mesmo, de sua validação e interpretação da legislação, mesmo em colegas que atuam conjuntamente em seu ambiente de trabalho, evidenciando que a própria comunidade TILS reconhece que, embora não seja regulamentado por Lei, que nem todos os TILS, apesar de obterem formação mínima, estão aptos para atuarem nos diversos ambientes pedagógicos.

Por outro lado, os profissionais também lutam arduamente para o trabalho em dupla, A realidade onde esse trabalho em conjunto é permitido, a troca é realizada no intervalo de 20 minutos, permitindo que o TILS descanse fisicamente e mantenha o contexto mental para apoiar 
o colega. Esse trabalho em dupla não significa a ausência de intervalo, de no mínimo, 15 minutos para a dupla, pois o cansaço mental envolvido no uso de ambas as línguas vivas é notável. Esta questão foi exposta por todos os entrevistados, que expuseram que é necessário com urgência que tenha a regulamentação da profissão para manter e justificar o trabalho realizado em dupla, fortalecendo a categoria.

Como expõe o sujeito $\mathrm{E}$, falando pelo grupo: “tivemos vários fatores positivos $e$ reconhecimento da profissão, acredito que o trabalho em dupla ainda seja um problema em alguns locais”. Como já citado, o trabalho em dupla já está sendo aceito em várias Instituições, através de lutas contínuas dos profissionais atuantes e pesquisas realizadas pela administração destes locais; porém, ainda há resistência de muitos ambientes pelo fato de falta de conhecimento da profissão, pela falta de profissionais habilitados, bem como falta de verba para financiar a contratação de mais TILS.

Observa-se que, atualmente, algumas instituições entendem a necessidade do trabalho em dupla, porém, grande parte ainda tem dificuldades para a prática de especificidade da profissão, o que causa um certo desconforto para quem não conhece a realidade desse 84 profissional. O que a comunidade expõe que é um grande progresso que precisa ser registrado e exigido através da Legislação, a atuação de, pelo menos dois profissionais por ato tradutório/interpretativo, onde a necessidade física e mental exige isso. Como mostra SANTOS (2012):

\begin{abstract}
Praticada cotidianamente no ambiente educacional, a interpretação de Libras por ser, na maioria das vezes simultânea exige muito do profissional, assim pretendo com este trabalho buscar e aprofundar argumentos que embasam a contratação de, no mínimo, dois profissionais por sala de aula. Portanto este trabalho tem também como objetivo discutir e justificar o trabalho de interpretação de libras em dupla. (SANTOS 2012, p 01)
\end{abstract}

Por outro lado, pode-se dizer que as conquistas dos TILS como profissão ocorreram paulatinamente, desde o início de sua profissão. É muito difícil relatar o momento exato no qual a profissão de TILS entrou no mercado de trabalho. Pereira (2008) relata:

Historicamente não é possível rastrear o exato momento em que os intérpretes começaram a atuar, mas é plausível imaginar que desde que os povos de diferentes línguas mantiveram contato houve, também, a necessidade de intérpretes. No caso das pessoas surdas, existem hipóteses de que a interpretação surgiu no meio familiar foi, aos poucos, se estendendo aos professores de crianças surdas e ao âmbito religioso. Com o passar do tempo, o fortalecimento dos movimentos sociais e políticos das 
comunidades surdas e reconhecimento legal das línguas de sinais surgiu, finalmente, o ILS profissional. (PEREIRA, 2008, p.138)

Conforme exposto, não há meios documentais que mostrem o exato momento de atuação do TILS, mas acredita-se que os familiares de surdos tiveram grande influência nessa profissão, como mostra Russo (2009):

[...] Apesar disso, temos relatos de pessoas ligadas a comunidade surda - amigos de surdos ou filhos ouvintes de pais surdos - em que estes atuavam como intérpretes durante idas ao médico, intermediando ligações telefônicas, conversas com gerente de banco, com advogados, com os padres, com familiares que não sabiam a língua de sinais, bem como em reuniões com os professores dos próprios filhos ouvintes nas escolas em que estes estudavam. (RUSSO 2009, p 27)

Os familiares que tinham mais interesse por esta língua, mediavam a comunicação com os demais, sendo propriamente dentro da família, ou no meio social externo. Há também relatos de interpretações realizadas no contexto religioso, o que ainda permanece até os dias de hoje.

A partir do momento em que a profissão TILS foi reconhecida, surgiu também a necessidade de formação específica. Cursos e capacitações começaram a ser oferecidos, culminando no curso de Letras-Libras, ofertado primeiramente, pela Universidade Federal de Santa Cataria - UFSC, na modalidade em EAD, com a formação, primeiramente de licenciados e bacharéis.

Russo (2009) também disserta que a visão de ser TILS como profissão ainda hoje não é bem difundida, já que muitos deles aceitam trabalhar voluntariamente. É claramente observado que a atuação voluntária pode ser feita, mas com o bom senso, não se deve desmerecer a profissão, pois a atuação do profissional TILS é reconhecida e solicitada como profissional, e tão exigida em legislação e pela comunidade surda em formação e fluência, que deve ser respeitada como tal.

Portanto, entre os pontos positivos percebidos nas falas dos sujeitos entrevistados, estão as possibilidades (ainda que não ideais) de formação. O trabalho em dupla também aparece como aspecto positivo (ainda que não encarado como regra padrão a todos os TILS em todos os contextos brasileiro).

Entre os pontos negativos, aparecem aspectos salariais e de saúde (como o aparecimento de lesões, como já explanado). Nesse sentido, o sujeito A expõe sua indignação ao afirmar que "não diria assustar, mas sim, entristecer o fato de que algumas instituições ainda pagam pouco e não aceitam o fato de que as duplas são necessárias [...]”.'. Observa-se que a luta por aceitação 
das duplas profissionais ainda é árdua e aparece repetitivamente nas falas dos entrevistados, pois na maioria dos locais ainda não entendem essa necessidade. Nem todas as instituições corroboram com a ideia do trabalho em dupla, por ser mais dispendioso. Portanto esta ainda é uma das lutas dos TILS, com o objetivo de facilitar o andamento do trabalho e proteger a saúde física e mental destes sujeitos.

Nas falas dos entrevistados também foi percebida a insatisfação com a falta regulamentação da profissão. Por mais que sejam reconhecidos pela CBO (Classificação Brasileira de Ocupações) sob o $\mathrm{n}^{\mathrm{o}}$ 261425, e pela Lei 12.319/2010, não existem regras específicas que padronizem a atuação, pois a legislação é muito abrangente. O decreto 5.626/2005 declara apenas que:

\footnotetext{
Nos próximos dez anos, a partir da publicação deste Decreto, a formação de tradutor e intérprete de Libras - Língua Portuguesa, em nível médio, deve ser realizada por meio de: I - cursos de educação profissional; II - cursos de extensão universitária; e III - cursos de formação continuada promovidos por instituições de ensino superior e instituições credenciadas por secretarias de educação. (BRASIL, 2005)
}

Esse artigo é um artefato importante para os TILS, já que prevê a formação do profissional. Contudo, a formação não é surpreendente, é mostrada em 2005 e reafirmada em 2010 na lei 12.319/2010. Não há novas legislações federais que avancem em vários aspectos que o decreto e a lei não contemplam, como por exemplo, o trabalho em duplas, piso salarial condizente com as horas de trabalho, questões de insalubridade no trabalho e de saúde, entre outros.

O sujeito E relata que a falta de regulamentação gera desconhecimento "de conhecimento de algumas pessoas no que diz respeito à profissão, tratando muitas vezes o intérprete como intruso e não como voz e meio de comunicação.” O sujeito F também cita que, pela falta de padrão na atuação TILS, há “[...] disparidade: umas intérpretes aceitam algumas condições de trabalho e outras não", gerando desnivelamento na atuação. O sujeito F continua ao dizer que a falta de regulamentação deixa a questão formativa também a desejar, ao dizer que "ficaria mais animada se esse problema fosse corrigido e se nos fosse oferecido cursos de aperfeiçoamento, plano de carreira, melhores condições de trabalho e regulamentação da profissão". A disparidade na atuação dos TILS é notável, onde, F complementa ao dizer que "Uns trabalham sozinhos e outros em dupla. Uns aceitam o valor da hora mais barata. Uns aceitam condições de trabalho mais precárias e outros lutam pelas condições. Isso desune a 
categoria, promove as disputas e não há avanços, muito menos coesão para a busca das conquistas desejadas".

O que "F" relata é de extrema relevância, pois há de se perceber a disparidade dentro da classe, em questões formativas, discursivas, o que dificulta ainda mais a valorização do TILS como classe. Na maioria dos casos, no que diz respeito a duplas para atuação, depende do entendimento do contratante para a efetivação dessa exigência, e na maioria dos casos, foi relatado pelos sujeitos entrevistados que os contratantes entendem que não há nenhuma obrigação por parte dos mesmos de se contratarem o trabalho em dupla.

Além disso, o atual código de ética, que orienta o profissional sobre a atuação, foi traduzido por Ricardo Sander, que originalmente é na língua inglesa, Interpreting for Deaf People, e aprovado no II Encontro Nacional de ILS, promovido pela FENEIS - Federação Nacional de Integração e Educação de Surdos - RJ em 1992.

Pode-se constatar que por mais que tenha um código de ética vigente, ele possui uma certa fragilidade, como mostra "C": "Uma das fragilidades do código de ética é que não tem ninguém para fiscalizar e fazer cumprir". A entrevistada opina que não há fisscalização para saber se realmente o código está sendo seguido corretamente por não haver um patamar legal, onde a legislação da União, ou estadual/municipal preveêm a obrigação de seu seguimento.

Também, a fala de "F" chama a atenção: "O código de ética é bem rigoroso. Acredito que as fragilidades sejam dos seres humanos e não do código, o mais comprometedor nessa profissão é a falta de regulamentação". Como se observa, a falta de regulamentação da profissão é bem preocupante, mas também, depende do bom senso de cada profissional na hora da atuação, e principalmente, do grupo de trabalho; já que o ideal, segundo os entrevistados é que todos os TILS têm de aderir à mesma postura.

"B" expõe sobre a impunidade: "A fragilidade estão onde alguns profissionais não respeitam o código de ética e não sofrerem nenhum tipo de penalidade”. O entrevistado salienta que realmente deveria ter uma fiscalização do trabalho dos profissionais, o que permitiria uma melhor postura e atuação do profissional.

Então, é notável observar nas falas dos entrevistados sobre a conduta e fiscalização dos profissionais atuantes, e ser de extrema importância que esse tipo de abordagem seja feita. 


\section{Considerações}

Ao observar as falas coletadas dos TILS, percebe-se que existem parâmetros pouco analisados na área que contempla os TILS, já que a comunidade acadêmica insiste em centralizar no ato tradutório/interpretativo e não em quem realiza esse trabalho e no que eles têm a dizer.

A partir deste artigo, observa-se que as falas dos sujeitos entrevistados giraram em torno de suas vivências dentro de sala de aula, relatando descontentamento no que tange à formação adequada, questões éticas, jornadas de trabalho e piso salarial; entretanto, ainda relatam felicidade em realizar seu trabalho e participarem pedagogicamente do desenvolvimento acadêmico de um sujeito surdo.

É notório que a legislação existe, como já mencionado, tanto para a inserção do sujeito surdo no âmbito público, como para a inserção do profissional TILS. Porém a diferença é que a Libras e suas particularidades vêm sendo temas de pesquisas, ao contrário de análises voltadas ao trabalho dos TILS, que entendem a profundidade do trabalho de um TILS, evidenciando assim a necessidade urgente de valorização em sentido profissional e salarial.

Os sujeitos de pesquisa mostraram que conhecem e seguem o código de ética vigente, porém relatam descontentamento com o mesmo em algumas questões que o código não trata especificamente, por exemplo, a falta de supervisão ética do profissional, o trabalho em dupla e a padronização salarial.

Conclui-se, portanto, que este estudo serviu para relatar narrativas de TILS no contexto da realidade em que estão inseridos, envolvendo seus descontentamentos e aspirações profissionais atuantes. Este artigo poderá servir como base de estudos para os próprios atuantes do Instituto Federal de Educação, Ciência e Tecnologia do Rio Grande do Sul, ou demais locais que tenha a atuação de profissionais TILS, para que se entenda a realidade do trabalho de um TILS, que se valorize a categoria e individualmente, bem como primar por um trabalho de qualidade.

\section{REFERÊNCIAS BIBLIOGRÁFICAS}

ALBRES, N.A.; DE LACERDA, C.B.F. Interpretação educacional como cmapo de pesquisa: estudo bibliométrico de publicações internacionais e suas marcas no campo nacional. Cadernos de Tradução, v.1, n.31,2013.

ALBRES, N.de A. Intérprete educacional: políticas e práticas em sala de aula inclusiva. São Paulo: Harmonia, 2015. 
ALBRES, N.de A. Dignidade acadêmica dos Estudos da Tradução. Disponível em: http://interpretaremlibras.blogspot.com.br/2009/03/dignidade-academica-dos-estudos-da.html Acesso: dezembro 2018

ALBRES, N.de A. A tradução e interpretação em Lingua de Sinais como objeto de estudo: produção acadêmica: 1980 a 2006. In: $2^{\circ}$ Encontro dos profissionais tradutores intérpretes de línguas brasileira de sinais de Mato Grosso do Sul. $2^{\circ}$ EPILMS, 2006, Campo Grande. Anais do $2^{\circ}$ EPILMS, v. 2. Campo Grande - MS: APILMS, 2006.

ANATER, G.,I.,P.; PASSOS, G.,C.,R., Tradutor e intérprete de Língua de Sinais: história, experiências e caminhos de formação, 2010. Disponível em: https://www.google.com.br/url?sa=t\&rct=j\&q=\&esrc=s\&source=web\&cd=2\&cad=rja\&ved= 0CDEQFjAB\&url=http\%3A\%2F\%2Fperiodicos.ufsc.br\%2Findex.php\%2Ftraducao\%2Farticl e\%2Fdownload\%2F2175-

7968.2010v2n26p207\%2F14229\&ei=LU5cUsGwFoLvqwHgzYCQBQ\&usg=AFQjCNHfbm 2FquD2HFki2P8au4MzY5PCWA Acesso: dezembro 2018

BARAZZUTTI, V. A desconstrução da oposição entre surdos e ouvintes a partir da (des)territorialização do intérprete de língua de sinais. 117p. Dissertação (Mestrado) Universidade Federal de Santa Catarina, Centro de Comunicação e Expressão. Programa de Pós-Graduação em Estudos da Tradução, Florianópolis, 2012.

BELÉM, L.J.M. A atuação do intérprete educacional de Lingua Brasileira de Sinais no ensino médio. 139p. Dissertação (mestrado). Universidade Metodista de Piracicaba, Faculdade de Ciências Humanas, Programa de Pós-Graduação em Educação, Piracicaba, 2010.

BRAGA, B.,C.; TRINDADE, C.,C.,B.

Intervençãofisioterápicaemlesõesporesforçosrepetitivosdecorrentes da utilização da LínguaBrasileira de SinaisContidoem: Salão de IniciaçãoCientífica (19. : 2007 : Porto Alegre, RS). Livro de resumos. Porto Alegre: UFRGS, 2007. Disponível em: http://hdl.handle.net/10183/57158 Acesso: dezembro 2018

BRASIL, Ministério da Educação. Instituto Nacional de Estudos e Pesquisas Educacionais Anísio Teixeira. Diretoria de Avaliação da Educação Básica. Atendimento Diferenciado ao ENEM. Brasília - DF, 2012. Disponível em:

http://download.inep.gov.br/educacao_basica/enem/nota_tecnica/2012/atendimento_diferenci ado_enem_2012.pdf Acesso: dezembro 2018

BRASIL, Presidência da República, Casa Civil, Subchefia Imediata para Assuntos Jurídicos. Decreto 5.626 de 22 de dezembro de 2005. Disponível em: http://www.planalto.gov.br/ccivil_03/_ato2004-2006/2005/decreto/d5626.htm Acesso: dezembro 2018

CONSTANCIO, R. F. J. O intérprete de Libras no ensino superior: sua atuação como mediador entre língua portuguesa e a língua de sinais. 106 p. Dissertação (Mestrado). Centro Universitário Moura Lacerda, Programa de Pós-Graduação em Educação, Ribeirão Preto - SP, 
2010.

COSTA, L. M. O tenso do intérprete de Libras no contexto do bilinguismo e o pretexto da inclusão. 109 p. Dissertação (Mestrado). Universidade Católica de Pernambuco, Programa de Pós-Graduação em Ciências da Linguagem, Recife, PE, 2008.

GURGEL, T. M. A. Práticas e formação de tradutores intérpretes de língua brasileira de sinais no ensino superior. 167p. Tese (Doutorado) - Universidade Metodista de Piracicaba, Faculdade de Ciências Humanas, Programa de Pós-Graduação, Piracicaba, SP, 2010.

LACERDA, C. B. F. A inclusão escolar de alunos surdos: o que dizem alunos, professores e intérpretes sobre essa experiência. Cad. Cedes, v. 26, n. 69, Campinas, p. 163-184, 2006.

LACERDA, C. B. F. Tradutores e intérpretes de Língua Brasileira de Sinais: Formação e atuação nos espaços educacionais inclusivos. Cadernos de Educação (Ufpel), v. 36, p.133$153,2010$.

LACERDA, C. B. F. A atuação do intérprete de Libras nos espaços educacionais: necessidades formativas. IN: I Congresso Nacional de Pesquisa em Tradução e Interpretação de Língua de Sinais Brasileira, Universidade Federal de Santa Catarina, Florianópolis, SC [não publicado], 2008.

90 LACERDA, C. B. F. O intérprete educacional de língua de sinais no ensino fundamental: refletindo sobre limites e possibilidades. IN: Ana Cláudia Lodi; Kathryn Pacheco Harrison; Sandra Leite de Campos; Ottmar Teske. (Org). Letramento e Minorias. Led. Porto Alegre: Editora Mediaão, v. p. 120-128. 2002.

MAGALHÃES JUNIOR, E. Sua majestade o intérprete: O fascinante mundo da interpretação simultânea. São Paulo: Parábola Editorial, 2007.

MARTINS, V. R. O. Educação de Surdos no paradoxo da inclusão com intérprete de língua de sinais: relações de poder e (re) criações do sujeito. 140p. Dissertação (Mestrado). Universidade Estadual de Campinas, Faculdade de Educação, Programa de Pós-Graduação em Educação, Campinas-SP, 2008.

MARTINEZ, M. C.; PARAGUAY, A. I. B. B. Satisfação e saúde no trabalho: aspectos conceituais e metodológicos. Cadernos de psicologia social do trabalho, 2003, 6: 59-78.

MASUTTI, M., L.; SANTOS, S., A. Intérpretes de Língua de Sinais: uma política em construção. In: QUADROS, R., M., (Org.). Estudos Surdos III, Petrópolis, RJ Arara Azul, 2008. Páginas 148-160. Disponível em:

http://www.libras.ufsc.br/colecaoLetrasLibras/eixoFormacaoEspecifica/traducaoEInterpretaca oDaLinguaDeSinais/assets/767/Link_Texto_1.pdf Acesso: dezembro 2018

NICOLOSO, S. Uma investigação sobre marcas de gênero na interpretação de língua de sinais brasileira. 200 p. Dissertação (Mestrado) - Universidade Federal de Santa Catarina, Centro de Ciência da Comunicação, Programa de Pós-Graduação em Estudos da Tradução, Florianópolis, 2010. 
PASSOS, G. C. R. Os intérpretes de lingua de sinais: atitudes frente a língua de sinais e às pessoas surdas. 142 p. Dissertação (Mestrado), Universidade Federal de Santa Catarina, Centro de Comunicação e Expressão, Programa de Pós-Graduação em Linguística, Florianópolis, 2010.

PÉREZ-RAMOS, J. Satisfação no trabalho: metas e tendências. Tese de Livre-docência, Instituto de Psicologia de Assis, Universidade Estadual Júlio de Mesquita Filho, Assis, 1980. QUADROS, R. O tradutor e intérprete de língua brasileira de sinais e língua portuguesa. Brasília: SEESP, 2002, 94p.

QUADROS, R. O tradutor e intérprete de língua brasileira de sinais e língua portuguesa. SEESP, 2004.

QUARESMA, J.; BONI, V. Aprendendo a entrevistar: como fazer entrevistas em Ciências Sociais. Revista Eletrônica dos Pós-Graduandos em Sociologia Política da UFSC, Florianópolis, Vol. 2 no 1 (3), janeiro-julho/2005, p. 68-80. Disponível em: https://periodicos.ufsc.br/index.php/emtese/article/view/18027/16976 Acesso: dezembro 2018

ROSA, A. da S. Entre a visibilidade da tradução da língua de sinais e a invisibilidade da tarefa do intérprete. 179 p. Dissertação (Mestrado). Universidade Estadual de Campinas, Faculdade de Educação, Programa de Pós-Graduação em Educação, Campinas - SP, 2005.

RUSSO, A. Intérprete de Língua Brasileira de Sinais: uma posição discursiva em construção. UFRGS. Porto Alegre, 2009. Disponível em: http://www.lume.ufrgs.br/bitstream/handle/10183/21851/000738782.pdf Acesso: dezembro 2018

SANTOS, S. A. Intérpretes de Lingua brasileira de sinais: um estudo sobre as identidades. Florianópolis, SC, 2007, v.188. Dissertação (Mestrado) - Universidade Federal de Santa Catarina, Centro de Ciências da Educação. Programa de Pós-Graduação em Educação, Florianópolis-SC, 2006.

SANTOS, J. Tradutor intérprete de Libras: Consolidando o trabalho em dupla. Trabalho apresentado no Congresso TILS, 2012, disponível em: http://www.congressotils.com.br/anais/tils2012_politicasdetraducao_santos.pdf Acesso: dezembro 2018

SANTOS, S.,F.Reino da Felicidade: comunidade surda e língua brasileira de sinais - relatos de uma professora surda - Ufpel. No prelo 2014.

SOUZA, S.X. Performances de tradução para a Lingua Brasileira de Sinais observadas no curso de Letras Libras - Florianópolis. 174p. Dissertação (Mestrado) - Universidade Federal de Santa Catarina, Centro de Comunicação e Expressão, Programa de Pós-Graduação em Estudos da Tradução, Florianópolis, 2010.

\footnotetext{
' Lucas de Almeida SOARES - Especialista em Tradução e Interpretação em Libras (2018) pela Faculdade EFICAZ. Licenciado em Ciências Sociais (2018) pela Universidade Luterana do Brasil. Graduando em 
Letras/Libras pela Faculdade Uniasselvi. É tradutor/Intérprete de Libras no Instituo Federal Sul-Rio-Grandense (IFSul) - Campus Pelotas. Pelotas, Rio Grande do Sul, Brasil.

Lattes: http://lattes.cnpq.br/1311910295710587 E-mail: lucas.ensino@gmail.com

ii Saionara dos Santos FIGUEIREDO - Doutoranda em Estudos da Tradução pela Universidade Federal de Santa Catarina. Mestre em Educação Ambiental (2013) pela Universidade Federal do Rio Grande. Especialista em Saúde Coletiva (2009) pelas Faculdades Integradas de Pato. Graduada em Pedagogia (2017) pelo Centro Universitário Paulistano. Graduada em Saneamento Ambiental (2009) pelo Instituto Centro de Ensino Tecnológico. É professora de Tradução no Instituto Federal de Santa Catarina (IFSC), campus Palhoça Bilíngue. Palhoça, Santa Catarina, Brasil.

Lattes: http://lattes.cnpq.br/1435988679423230 E-mail: saionara.figueiredo@gmail.com

1 TILS: Tradutor e Intérprete de Língua de Sinais, neste contexto, utilizaremos para direcionar ao Tradutor e Intérprete de Língua Brasileira de Sinais. 